\title{
Effect of Stimulus Intensity on Prolactin and Cortisol Release Induced by Unilateral Electroconvulsive Therapy
}

\author{
Athanasios P. Zis, M.D., Lakshmi N. Yatham, M.D., Raymond W. Lam, M.D., \\ Campbell M. Clark, Ph.D., Manit Srisurapanont, M.D., and Kathleen McGarvey, M.D.
}

Prolactin (PRL) plasma levels rise several fold in response to electroconiulsive therapy (ECT). There is evidence that the magnitude of ECT-induced PRL release varies as a function of electrode placement with bilateral (BL) ECT, producing a larger PRL increase than does unilateral (UL) ECT. Although there is some eridence that the amount of PRL released by ECT may also vary as a function of stimulus intensity, the effect of stimulus intensity on the amount of PRL relensed by UL ECT has not been studied. This is an inportant question because it is aith UL electrode placement that large differences in clinical efficacy as a function of stimulus intensity ha'e been documented. We studied patients undergoing a course of UL ECT as the clinically indicated treatment for their illness. Subjects received low-dose (threshold) and high-dose (three times the threshold) ECT on two consecutioe treatments. The order of low-ant high-dose treatments was comnterbalanced. Blood

KEY WORDS: Electroconiulsioe therapy (ECT); Prolactin; Cortisol; Seizures; Stimulus intensity

From the Division of Mood Disorders, Department of J'sychiatry University of British Columbia, Vancouver, Canada.

Address correspondence to: Dr. A. P. Zis, Department of Psychiatry, University of British Columbia, 2255 Wesbrook Mall, Vancouver, B.C. V6T 2A1. Tel: 822-7325 Fax: 822-7922

Received May 25, 1995; revised September 13, 1995; accepted September $28,1995$. samples were drawn at 15-minute intervals before and for 1 hour after the administration of ECT and assayed for PRL and cortisol levels. Our results clearly indicate that the PRL and cortisol response to UL ECT-induced PRL release waries as a function of stimulus intensity. In fact, the amount of PRL released by high-dose UL ECT was nearly three times greater than that released by threshold stimulation. These results are consistent with the hypothesis advocating that the therapeutic advantage of high-intensity over low-intensity UL ECT is the result of greater seizure generalization and spread to subcortical regions and suggest that ECT-induced PRL release has the potential to distinguish a seizure induced by a therapeutic stimulus from a seizure induced by a stimulus known to have little therapentic effect. [Neuropsychopharmacology 15:263-270, 1996]

Sixty years after its introduction and despite the advent of modern psychopharmacology, electroconvulsive therapy (ECT) remains an essential therapeutic modality for the severely mentally ill patient. The indications for ECT include depression, mania, and catatonia, and recent observations suggest that it also alleviates symptoms of Parkinson's disease (Fink 1993). However, the mechanism of action of ECT remains unknown. Since the 1960s the clinical practice of ECT and the investigation of its mechanism of action have relied on two basic principles. First, that the seizure activity is the essential therapeutic element with the passage of current being only a method of seizure induction, and second, that 
the duration of seizure activity is a valid index of clinical efficacy. These principles were based primarily on clinical studies demonstrating that chemically induced (e.g., with flurothyl) seizures are effective for the treatment of depression (reviewed by Fink 1979) and that lidocaine pretreatment reduces both seizure duration and the benefits of treatment (Ottosson 1960). Although there is considerable evidence that the induction of a generalized seizure is an essential requirement for the therapeutic effect of ECT, the view that the induction of seizure activity of a certain duration alone is sufficient had been questioned (Deakin 1983; Abrams 1986). Convincing evidence to challenge this long-held view was provided recently by Sackeim et al. (1993), who demonstrated that low-intensity unilateral (UL) ECT resulted in generalized seizures of adequate duration but with little or no therapeutic benefit. This observation has important implications not only for the clinical practice of ECT but also for the methods used to investigate the mechanisms underlying its therapeutic effect.

The major difficulty in understanding how ECT works has to do with the fact that the induction of a generalized seizure is associated with multiple biochemical effects that makes it very difficult to isolate those changes responsible for the therapeutic effect of ECT (Kety 1974; Sackeim and Devanand 1990). However, because generalized seizures of adequate duration can be induced with little or no clinical effect (Sackeim et al. 1993), depending on the stimulus intensity and electrode placement, we now know that all ECT seizures are not the same. Therefore, by manipulating the parameters of the method of seizure induction, there is now an opportunity to identify those neurochemical effects which may be related to the mechanism of action of ECT.

Prolactin (PRL) plasma levels rise several fold in response to ECT. This neuroendocrine response has been described as "one of the most unanimous findings in psychoneuroendocrinology" (Baumgartner et al. 1988) and as "by far the most consistent neurochemical result of ECT-induced seizures," (Abrams 1992). There is evidence that the magnitude of ECT-induced PRL release varies as a function of electrode placement with bilateral (BL) ECT producing a larger PRL increase than UL. ECT (Papakostas et al. 1984; Swartz and Abrams 1984; $Z$ is et al. 1991). Although there is some evidence that the amount of PRL released by ECT may also vary as a function of stimulus intensity (Robin et al., 1985; Abrams and Swartz 1985; Zis et al. 1993), the effect of stimulus intensity on the amount of PRL released by L'L ECT had not been studied, although large differences have been documented in the clinical efficacy of UL ECT as a function of stimulus intensity (Sackeim et al. 1993). We report here the results of our investigation of the effect of low-and high-intensity UL ECT, known to differ widely in clinical efficacy, or PRL and cortisol re- lease and discuss the theoretical and clinical implications of our findings.

\section{Methods}

\section{Subjects}

Subjects of this study were consecutive patients undergoing a course of UL ECT as the clinically indicated treatment for major depression. All subjects gave written informed consent prior to participation in the study as approved by the Ethics Committee of the University of British Columbia. We studied 10 patients, 7 women and 3 men. The mean age was 55 years and ranged between 33 and 79 years (Table 1). All subjects had been psychotropic drug free for at least 2 weeks prior to the two study treatments, with the exception of small doses of lorazepam (1-6 mg daily). The dose of lorazepam for each patient was kept constant throughout the study. Three patients (\#5, 6, and 9) were maintained on L-thyroxine. One patient (\#4) was on maintenance oral antidiabetic (glyburide) and ranitidine. One patient (\#7) was on maintenance conjugated estrogens, and one patient (\#10) was maintained on cholestyramine and lovastatin to lower blood cholesterol levels. Doses of all these maintenance medications remained constant throughout the study.

\section{Electroconvulsive Therapy}

At our institution ECT treatments are given three times a week. Anaesthesia is induced by sodium thiopental and muscle relaxation is achieved by succinylcholine administration. Seizure threshold is carefully quantified at the first treatment by the empirical titration procedure (Sackeim et al. 1993), and in the case of UL ECT subsequent treatments are administered with an intensity three to five times the seizure threshold. For this study we quantified seizure threshold using the Thymatron ECT apparatus with Flexdial Controller (Somatics, Inc., Lake Bluff, IL). Frequency was set at $70 \mathrm{~Hz}$, pulse width at $1 \mathrm{msec}$, and current at $0.9 \mathrm{~A}$ as set by the manufacturer. The duration of the stimulus was the only variable manipulated to determine seizure threshold and deliver the treatments. Starting with the lowest setting on the Thymatron (electrical charge at $25.2 \mathrm{mC}$ ), electrical stimulations were given at levels of increasingly higher intensity (in 25.2- $\mathrm{mC}$ increments) until a generalized tonic-clonic seizure lasting at least $25 \mathrm{sec}-$ onds was induced. Electrode placement was right UL (d'Elia method). Seizure duration was monitored by the pressure cuff method (Fink and Johnson 1982) from the onset of electrical stimulation until all motor seizure activity stopped. The doses of sodium thiopental and suc- 
cinylcholine ranged between 125 and $250 \mathrm{mg}$ and 30 and $60 \mathrm{mg}$, respectively, and remained constant for each patient.

\section{Study Design}

We used a within-subject double-blind study design. The patient and technician performing the hormonal assays were blind as to the order of stimulus intensity. On the two study treatments (\#3 and \#4) the patient received either a stimulus of threshold charge or a stimulus charge that was three times the threshold. The order was counterbalanced randomly with five patients (subjects \#3, 5, 8, 9, and 10 ) receiving threshold stimulation on treatment \#3 and three times the threshold stimulation on treatment \#4. The order was reversed in the other five patients.

Prolactin and Cortisol Measurements. An intravenous catheter was placed in the left forearm 1 hour prior to the administration of ECT to measure ECT-induced PRL and cortisol release on treatment \#3 and \#4. Blood samples were collected 15 minutes before, immediately before the administration of anesthesia, and at 15minute intervals for 1 hour after the administration of the electrical stimulus. PRL was measured by an immunochemiluminometric (ICMA) assay run on the CibaCorning ACS analyzer. All samples from each patient were analyzed within the same assay. The sensitivity of this assay is $0.3 / \mu \mathrm{g} / \mathrm{L}$. Typical interassay coefficients of variation are $5.3 \%$ for a level of $10 \mu \mathrm{g} / \mathrm{L}$ and $5 \%$ for a level of $43.5 \mu \mathrm{g} / \mathrm{L}$. Typical intraassay coefficients of variation are $2.8 \%$ for a level of $2.7 / \mu \mathrm{g} / \mathrm{L}$ and $3.8 \%$ for a level of $121 \mu \mathrm{g} / \mathrm{L}$. Cortisol was measured by a fluorescent polarization immunoassay (Abbott Laboratories). All samples from each patient were analyzed within the same assay. The sensitivity of this assay is $69 \mathrm{nmol} / \mathrm{L}$. Typical interassay coefficients of variation are $7.8 \%$, for a level of $110 \mathrm{nmol} / \mathrm{L}$ and $1.8 \%$ for a level of $1,084 \mathrm{nmol} / \mathrm{L}$. Typical intraassay coefficients of variation are $6.4 \%$ for a level of $110 \mathrm{nmol} / \mathrm{L}$ and $3.1 \%$ for a level of $1,084 \mathrm{nmol} / \mathrm{L}$.

\section{Statistical Analysis}

The data were analyzed by analysis of variance (ANOVA) $[2$ (intensity) $\times 6$ (time) $]$ with repeated-measures on both factors, the Student's $t$ test for paired data (twotailed), and the Pearson's $r$ (two-tailed).

\section{RESULTS}

The age, sex, seizure threshold, as well as stimulus charge and seizure duration for low-dose and highdose UL ECT, are presented in Table 1. The effect of stimulus intensity on ECT-induced PRL release is depicted in Figure 1. A repeated-measures ANOVA indicated a significant time effect $(F=13.57$, df $=45,5, p<$ $.01)$, a significant group effect $(F=7.98, \mathrm{df}=9,1, p=$ $.02)$, and a significant time-by-group interaction $(F=$ $5.93, \mathrm{df}=45,5, p<.01)$. Paired $t$ tests indicated that there was no difference at baseline ( $p=.03$ for both -15 and 0 time points paired $t$ test, two-tailed). Table 2 shows the baseline PRL values (the mean of -15 and 0 time point levels), $\Delta$ - PRL (the difference between maximal post-ECT PRL level and baseline), and the area under the curve (AUC) - PRL for each individual patient and for each of the two experimental conditions. Both mean $\triangle$ - PRL and mean AUC - PRL were significantly higher in response to high-dose UL ECT than to low-dose UL ECT ( $p<.05$, paired $t$ test, two-tailed). For all subjects (in the case of AUC - PRL) and 9 of 10 subjects (in the case of $\Delta$ - PRL) the amount of PRL released in response to high-dose UL ECT exceeded that released by low-dose LL ECT. Moreover, the amount of PRL released by high-dose UL ECT relative to that released by low-dose UL ECT was nearly identical to the proportion to which stimulus intensity of high-dose UL ECT exceeded that of low-dose UL ECT relative to the threshold. Specifically, the ratio of the high-dose and low-dose UL ECT was 2.49 and 2.64 for $\Delta$ - PRL and AUC - PRL, respectively.

The effect of stimulus intensity on ECT-induced cortisol release is depicted in Figure 2. A repeated-measures ANOVA indicated a significant time effect $(F=$ $18.09, \mathrm{df}=45,5, p<.01)$, a significant group effect $(F=$ $33.53, \mathrm{df}=9,1, p<.001)$, and a significant group-bytime interaction $(F=5.71, \mathrm{df}=45,5, p<.01)$. Paired $t$

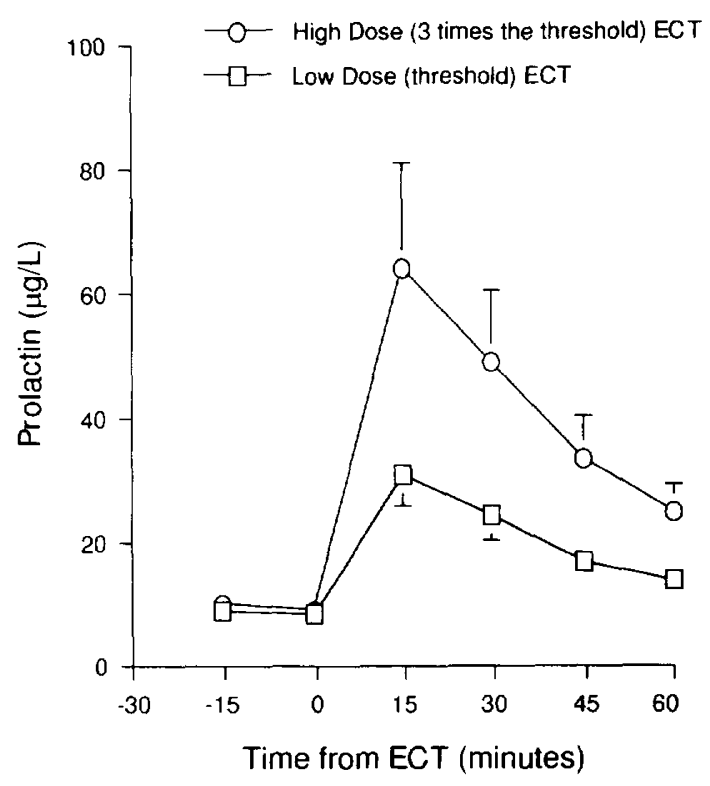

Figure 1. Effect of stimulus intensity on UL ECT-induced PRL release (means \pm SEM) 
Table 1. Demographics, Treatment Parameters and Seizure Duration

\begin{tabular}{|c|c|c|c|c|c|c|c|}
\hline \multirow[b]{2}{*}{ Subject \# } & \multirow[b]{2}{*}{ Sex } & \multirow[b]{2}{*}{ Age } & \multirow[b]{2}{*}{$\begin{array}{l}\text { Seizure } \\
\text { Threshold } \\
\text { (mC) }\end{array}$} & \multicolumn{2}{|c|}{$\begin{array}{c}\text { Low-Dose (threshold) } \\
\text { UL ECT }\end{array}$} & \multicolumn{2}{|c|}{$\begin{array}{l}\text { High-Dose (3 times } \\
\text { the threshold) UL ECT }\end{array}$} \\
\hline & & & & $\begin{array}{c}\text { Stimulus } \\
\text { Charge } \\
\text { (mC) }\end{array}$ & $\begin{array}{l}\text { Seizure } \\
\text { Duration } \\
\text { (s) }\end{array}$ & $\begin{array}{c}\text { Stimulus } \\
\text { Charge } \\
\text { (mC) }\end{array}$ & $\begin{array}{c}\text { Seizure } \\
\text { Duration } \\
\text { (s) }\end{array}$ \\
\hline 1 & $\mathrm{~F}$ & 42 & 50.4 & 50.4 & 22 & 151.2 & 25 \\
\hline 2 & $\mathrm{~F}$ & 33 & 50.4 & 50.4 & 40 & 151.2 & 35 \\
\hline 3 & $\mathrm{~F}$ & 59 & 50.4 & 50.4 & 35 & 151.2 & 35 \\
\hline 4 & $\mathrm{M}$ & 60 & 50.4 & 50.4 & 35 & 151.2 & 35 \\
\hline 5 & $F$ & 79 & 126.0 & 126.0 & 27 & 378.0 & 35 \\
\hline 6 & $\mathrm{M}$ & 69 & 126.0 & 126.0 & 25 & 378.0 & 35 \\
\hline 7 & $\mathrm{~F}$ & 50 & 50.4 & 50.4 & 20 & 151.2 & 45 \\
\hline 8 & $\mathrm{M}$ & 40 & 75.6 & 75.6 & 63 & 226.8 & 45 \\
\hline 9 & $\mathrm{~F}$ & 49 & 50.4 & 50.4 & 32 & 151.2 & 33 \\
\hline 10 & $\mathrm{~F}$ & 67 & 75.6 & 75.6 & 35 & 226.8 & 35 \\
\hline $\bar{X} \pm S D$ & & $55 \pm 15$ & $71 \pm 31$ & $71 \pm 31$ & $33 \pm 12$ & $212 \pm 93$ & $36 \pm 6$ \\
\hline
\end{tabular}

tests indicated that there was no difference at baseline $(p=.8$ and .7 for the -15 and 0 time points, respectively). Table 3 presents the baseline cortisol values (the mean of -15 and 0 time point levels), $\Delta$ - cort (the difference between maximal post-ECT cortisol levels and baseline) and the AUC - cort for each individual patient and for each of the two experimental conditions. Both mean $\triangle-$ cort and AUC - cort values were significantly higher in response to high-dose UL ECT than to low-dose UL ECT $(p<.05$, paired $t$ test, two-tailed). For 9 out of 10 subjects (in the case of $\lrcorner-$ cort) and 8 out of 10 subjects (in the case of ALC - cort) the amount of cortisol released in response to high-dose LL ECT exceeded that released by low-dose LL ECT. The ratio of the mean cortisol released by high-dose UL ECT rela- tive to that released by low-dose UL ECT was 2.1 for AUC - cort and 1.6 for $\Delta$ - cort.

There was no difference in seizure duration between low-dose and high-dose UL ECT ( $p=.51$, paired $t$-test). There was no significant relationship between seizure duration and $\Delta-$ PRL in response to low-dose UL ECT and only a trend toward a significant relationship with high-dose UL ECT $(r=-.15$ and $r=.57$ for low-dose and high-dose ECT, respectively, Pearsons $r, \mathrm{df}=8$, two-tailed). The relationship between seizure duration and $\Delta-$ cort was not significant either $(r=.29$ and $r=$ .08 for low- and high-dose UL ECT, respectively, Pearson's $r, \mathrm{df}=8$, two-tailed). There was also no relationship between absolute electrical dosage and $\Delta$ - PRL $(r=-.15$ and $r=-.09$ for low- and high-dose UL ECT,

Table 2. Effect of Stimulus Intensity on LL ECT-Induced Prolactin Release

\begin{tabular}{|c|c|c|c|c|c|c|}
\hline \multirow[b]{2}{*}{ Subject \# } & \multicolumn{3}{|c|}{ Low Dose (Threshold) UL ECT } & \multicolumn{3}{|c|}{ High Dose ( 3 times The Threshold) UL ECT } \\
\hline & $\begin{array}{l}\text { Baseline }^{t i} \\
(\mu \mathrm{g} / \mathrm{L})\end{array}$ & $\begin{array}{c}\perp \mathrm{PRL}^{b} \\
(\mu \mathrm{g} / \mathrm{L})\end{array}$ & $\begin{array}{c}\text { AUC }-P R L^{\circ} \\
(\mu \mathrm{g} / \mathrm{L} / \mathrm{min})\end{array}$ & $\begin{array}{l}\text { Baseline }^{a} \\
(\mu \mathrm{g} / \mathrm{L})\end{array}$ & $\begin{array}{c}د-\text { PRL }^{b} \\
(\mu \mathrm{g} / \mathrm{L})\end{array}$ & $\begin{array}{c}\text { AUC }- \text { PRL }^{c} \\
(\mu \mathrm{g} / \mathrm{L} / \mathrm{min})\end{array}$ \\
\hline 1 & 14.9 & 19.1 & 482 & 13.3 & 17.7 & 626 \\
\hline 2 & 13.8 & 40.2 & 1,142 & 18.7 & 78.3 & 2,581 \\
\hline 3 & 6.7 & 4.2 & 128 & 6.9 & 8.6 & 306 \\
\hline 4 & 8.3 & 8.2 & 243 & 6.5 & 20.5 & 835 \\
\hline 5 & 7.8 & 29.2 & 920 & 11.4 & 87.6 & 3,399 \\
\hline 6 & 5.7 & 9.4 & 405 & 6.2 & 15.8 & 629 \\
\hline 7 & 11.7 & 46.3 & 1,530 & 8.2 & 185.3 & 6,036 \\
\hline 8 & 8.6 & 20.4 & 679 & 8.5 & 45.5 & 1,487 \\
\hline 9 & 5.3 & 26.7 & 950 & 4.7 & 58.3 & 2,071 \\
\hline 10 & 4.4 & 17.5 & 680 & 7.9 & 24.1 & 953 \\
\hline $\mathrm{x} \pm \mathrm{SD}$ & $8.7 \pm 3.6$ & $22.1 \pm 13.7$ & $716 \pm 430$ & $9.2 \pm 4.2$ & $54.2^{d} \pm 53.7$ & $1,892^{d} \pm 1,758$ \\
\hline
\end{tabular}

"Mean of -15 and 0 time points.

"Maximal post ECT value minus baseline

'Area under the' curve.

"Significantly greater than low-dose UL FCT $(p<.05$, paired two-tailed test). 


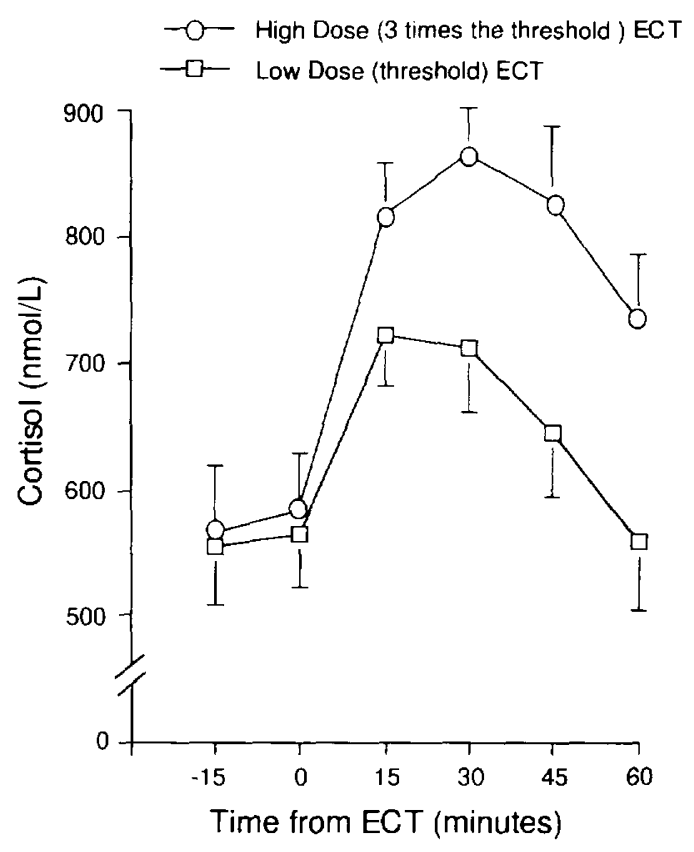

Figure 2. Effect of stimulus intensity on UL ECT-induced cortisol release (means $\pm \mathrm{SEM}$ ).

respectively, Pearson's $r$, $\mathrm{df}=8$ ) nor between absolute electrical dosage and $\lrcorner-\operatorname{cort}(r=-.22$ and $r=-.05)$ for low- and high-dose LL ECT, respectively (Pearson's $r, \mathrm{df}=8$, two-tailed).

\section{DISCUSSION}

The results of this study demonstrate for the first time that UL ECT-induced PRL release varies as a function of stimulus intensity. More specifically, they show that the amount of PRL released by a stimulus intensity that exceeds the seizure threshold by a factor of 3 was nearly as many times greater that the amount released by threshold stimulation. We also examined for the first time the effect of stimulus intensity on cortisol release. Overall the effect of ECT on cortisol levels was more prolonged than and not as large as the effect on PRL, an observation consistent with earlier reports (Haskett et al. 1985). Nevertheless, the amount of cortisol released by high-dose UL ECT was significantly greater (approximately twofold) than that released by low-dose ECT. The much larger PRL and cortisol release in response to high-dose ECT cannot be attributed to differences in seizure duration as there was no significant difference in seizure duration between high- and low-dose ECT groups. Furthermore, there was no significant relationship between seizure duration and prolactin or cortisol release, a finding consistent with the results of several (Swartz and Abrams 1984; Aperia et al. 1985; Zis et al. 1991), but not all (Balldin 1983; Mitchell et al. 1990), studies. The lack of a relationship between absolute electrical dosage and PRL and cortisol release, despite the much greater release in response to high-intensity stimulation, suggests that the magnitude of PRL and cortisol release is influenced not by absolute dosage, but by whether, and perhaps also the extent to which, the stimulus intensity exceeds the patient's seizure threshold.

These observations may have implications for the research aimed at improving the clinical practice of ECT. In view of the evidence that low-dose UL ECT results in generalized seizures of adequate duration with little therapeutic benefit, the principle that the duration of seizure activity is a valid index of clinical efficacy is no

Table 3. Effect of Stimulus Intensity on UL ECT-Induced Cortisol Release

\begin{tabular}{|c|c|c|c|c|c|c|}
\hline \multirow[b]{2}{*}{ Subject \# } & \multicolumn{3}{|c|}{ Low Dose (Threshold) ECT } & \multicolumn{3}{|c|}{ High Dose (3 Times The Threshold) ECT } \\
\hline & $\begin{array}{c}\text { Baseline }^{l l} \\
(\mathrm{nmol} / \mathrm{L})\end{array}$ & $\begin{array}{l}J-\operatorname{cort}^{b} \\
(\mathrm{nmol} / \mathrm{L})\end{array}$ & $\begin{array}{l}\text { AUC }- \text { Cort }^{c} \\
(\mathrm{nmol} / \mathrm{L} / \mathrm{min})\end{array}$ & $\begin{array}{l}\text { Baseline }^{a} \\
(\mathrm{nmol} / \mathrm{L})\end{array}$ & $\begin{array}{l}J-\text { cort }^{b} \\
\left(\mathrm{nmol}^{\prime} \mathrm{L}\right)\end{array}$ & $\begin{array}{l}\text { AUC - Cort' } \\
(\mathrm{nmol} / \mathrm{L} / \mathrm{min})\end{array}$ \\
\hline 1 & 567 & 174 & 5,633 & 598 & 191 & 8,145 \\
\hline 2 & 577 & 105 & 2,895 & 728 & 36 & 69 \\
\hline 3 & 582 & 129 & 1,928 & 514 & 441 & 18,975 \\
\hline 4 & 542 & 33 & $-1,988$ & 400 & 333 & 13,978 \\
\hline 5 & 674 & 123 & 324 & 592 & 440 & 17,805 \\
\hline 6 & 523 & 45 & 391 & 543 & 81 & 631 \\
\hline 7 & 681 & 153 & 2,033 & 765 & 237 & 10,868 \\
\hline 8 & 471 & 304 & 13,387 & 465 & 357 & 17,723 \\
\hline 9 & 254 & 483 & 21,623 & 351 & 494 & 22,590 \\
\hline 10 & 735 & 360 & 14,400 & 790 & 396 & 16,800 \\
\hline$x \pm S D$ & $561 \pm 134$ & $191 \pm 145$ & $6,062 \pm 7,737$ & $575 \pm 151$ & $304^{d} \pm 158$ & $12,754^{d} \pm 7,718$ \\
\hline
\end{tabular}

"Mean of -15 and 0 time points.

"Maximal post ECT value' minus baseline'

Area under the curve.

"Significantly greater than low-dose UL ECT (p)...5, paired two-tailed test). 
longer tenable (Sackeim et al. 1993; Swartz 1993). Research to find a substitute for seizure duration has recently focused primarily on ictal electroencephalogram(EEG) based indices because some of these indices (e.g., the degree of postictal EEG suppression) have been shown to distinguish forms of ECT that differ in therapeutic efficacy (Krystal et al. 1993; Nobler et al. 1993; Swartz 1993; Krystal and Weiner 1994). The relationship however, between EEG indices and clinical outcome, although statistically significant, has yet to prove sufficiently robust in terms of specificity and sensitivity to be of practical use (Sackeim 1994a). Given the fact that ECT-induced PRL release is both a robust and reliable phenomenon, this neuroendocrine response has also received consideration as a possible marker of treatment adequacy (i.e., as an indication that a therapeutic treatment has been delivered). Although one study was unable to detect any relationship between PRL release and clinical improvement (Deakin et al. 1983) and another reported a negative relationship between mean PRL response over the first four treatments and global improvement ratings after six treatments or total number of treatments (Abrams and Swartz 1985), one study did find a positive correlation between PRL response to the first ECT and percent clinical improvement on the Hamilton Rating Scale for Depression (HRSD) (Whalley et al. 1987), and another reported that the PRL response to the first ECT was twice as high in responders as in nonresponders, although the difference was not statistically significant and although there was no relationship between PRL release and percent improvement on the HRSD (Scott et al., 1986). More recently Clark et al. (1995) found no relationship between PRL release and early response (after six treatments) to ECT, but they did report a trend approaching statistical significance for the relationship between PRL release and final outcome. Although the results of these studies are inconclusive, in view of the present data indicating that ECTinduced PRL release can distinguish forms of ECT that differ in therapeutic efficacy, we would like to suggest that research in that direction should be continued.

In the light of the evidence that UL threshold stimulation has little therapeutic effect compared to treatment with a stimulus exceeding the threshold two to three times (Sackeim et al. 1993), the observation that the amount of PRL (and cortisol) released by UL ECT was two to three times greater when the stimulus intensity exceeded three times the threshold may also have implications for ECT theory. One of the hypotheses proposed to explain the therapeutic advantage of $\mathrm{BL}$ and high-intensity UL ECT over low-intensity UL ECT (Sackeim et al. 1993) is that BL and high-intensity UL ECT are the result of greater seizure generalization and spread of seizure activity to subcortical regions (Abrams $1986,1991,1992)$. It has been known for some time that
ECT-induced PRL release is greater in BL treatment than in UL treatment (Papakostas et al. 1984; Swartz and Abrams 1984; Zis et al. 1991). The present data indicate that the amount of PRL released is also greater in response to high-intensity than in response to lowintensity UL ECT. These observations are consistent with the hypothesis advocating that the therapeutic superiority of BL and high-intensity UL ECT over lowintensity UL ECT is the result of greater spread of seizure activity to diencephalic regions for several reasons. The hypothalamus controls the regulation of PRL release, and therefore it is quite plausible to argue that the amount of PRL released in response to ECT depends on the spread of the seizure activity to subcortical areas. A direct link between PRL release and spread of seizure activity to subcortical areas comes from studies using intracerebral electrodes that showed that PRL release in response to electrical stimulation, as well as PRL release after spontaneous complex partial seizures, is contingent on the seizure activity spreading to subcortical structures (ventromedial hypothalamus) (Sperling and Wilson 1986; Sperling et al. 1986). The hypothesis of a better spread of the seizure activity to subcortical areas is also supported by the fact that high-intensity ECT is associated with a greater release not only of PRL but also of other hormones under hypothalamic control, such as cortisol (as reported herein) and oxytocin (Riddle et al. 1993).

It must be pointed out, however, that not all ECT theorists agree with the view that the therapeutic advantage of $\mathrm{BL}$ and high-intensity ULECT is the result of the seizure activity spreading at the level of the diencephalon. Thus Sackeim (1994) has argued that whether or not the seizure activity spreads to the diencephalon may be irrelevant and that the intensity and topography of postictal physiological changes are what is essential to the therapeutic effect. Based on evidence suggesting that current density in various brain areas may vary as a function of electrode placement and stimulus intensity, he argues that with low-intensity (threshold) ECT seizures initiate from the peri-Rolandic area (motor strip) of the cerebral cortex, whereas BL and highintensity seizures initiate at "a wider lateralized network involving anterior frontal regions" and that any changes in diencephalic (hypothalamic) function are secondary (downstream) to the cortical effects. Whether, according to Sackeim (1994b), these downstream effects are essential to the therapeutic effect of ECT remains an open question. Although such a viewpoint does imply that ECT-induced PRL release may not be a useful method for testing hypotheses advocating a role for the diencephalon in the mechanism of action of ECT, it does not preclude its utility as a useful measure that an effective treatment has been delivered. Thus it is plausible to argue that even if these downstream effects were to 
prove irrelevant to the mechanism of action of ECT and that effects at the cerebral (prefrontal) cortex alone were the essential therapeutic ingredient, the cortical effects must be of such intensity and topography as to induce substantial physiological effects at the level of the diencephalon (e.g., hypothalamic stimulation and hormonal release). The fact that BL and high-intensity ULECT are associated with both greater therapeutic effect and greater PRL release supports this contention.

\section{ACKNOWLEDGMENTS}

The assistance of A. O'Brien, J. Eyre, and J. Thomson is gratefully acknowledged. This study was supported by a grant from the Medical Research Council of Canada (MT-10615)

\section{REFERENCES}

Abrams R (1986): A hypothesis to explain divergent findings among studies comparing the efficacy of unilateral and bilateral ECT in depression. Convuls Ther 2:253-257

Abrams R (1991): Invited Commentary: Seizure generalization and unilateral electroconvulsive therapy. Convuls Ther $7(3): 213-217$

Abrams R (1992): Electroconvulsive Therapy, ed 2. New York, Oxford University Press

Abrams R, Swartz CM (1985): ECT and prolactin release: Relation to treatment response in melancholia. Convuls Ther 1:38-42

Aperia B, Thoren M, Wetterberg L (1985): Prolactin and thyrotropin in serum during electroconvulsive therapy in patients with major depressive illness. Acta Psychiatr Scand 72:302-309

Balldin J (1983): Factors influencing prolactin release induced by electroconvulsive therapy. Acta Psyciatr Scand 65: $365-369$

Baumgartner A, Graf K-J, Kurten I (1988): Prolactin in patients with major depressive disorder and in healthy subjects: I. Cross-sectional study of basal and post-TRH and postdexamethasone prolactin levels. Biol Psychiatry $24(3): 249-267$

Clark CP, Alexopoulos GS, Kaplan J (1995): Prolactin release and clinical response to electroconvulsive therapy in depressed geriatric inpatients: A preliminary report. Convuls Ther 11:2t-31

Deakin JFW (1983): Antidepressant effect of electroconvulsive therapy: Current or seizure? Br Med J 126:10831084

Deakin JFW, Ferrier IN, Crow TJ, Johnstone EC, Lawler I (1983): Effects of ECT on pituitary hormone release: Relationship to seizure, clinical variables and outcome. Br J Psychiatry 143:618-624

Fink M (1979): Convulsive Therapy: Theory and Practice. New' York, Raven
Fink M (1993): Whom should get ECT? In Coffey CE (ed). The Clinical Science of Electroconvulsive Therapy. Washington, DC, American Psychiatric Press, 3-15

Fink M, Johnson L (1982): Monitoring the duration of electroconvulsive therapy seizure: $<<\mathrm{Cuff}>>$ and EEG methods compared. Arch Gen Psychiatry 39:1189-1191

Haskett RF, Zis AP, Albala AA (1985): Hormone response to repeated electroconvulsive therapy. Effects of naloxone. Biol Psychiatr 20:623-633

Kety S (1974): Biochemical and neurochemical effects of electroconvulsive shock. In Fink M, Kety S, McGaugh $\mathrm{T}$ (eds), Psychobiology of Convulsive Therapy. Washington, DC, Winston and Sons, pp 285-294

Krystal AD, Weiner RD (1994): ECT seizure therapeutic adequacy. Convuls Ther 10(2):153-164

Krystal AD, Weiner RD, McCall WV, Shelp FE, Arias R, Smith P (1993): The effects of ECT stimulus dose and electrode placement on the ictal electroencephalogram: An intraindividual crossover study. Biol Psychiatry 34:759-767

Mitchell P, Smythe G, Torda T (1990): Effect of anaesthetic agent propofol on hormonal responses to ECT. Biol Psychiatry 28:315-324

Nobler MS, Sackeim HA, Solomou M, Luber B, Devanand DP, Prudic J (1993): EEG manifestations during ECT: Effects of electrode placement and stimulus intensity. Biol Psychiatry 34(5):321-330

Ottosson J-O (1960): Experimental studies of the mode of action of electroconvulsive therapy. Acta Psychiatr Neurol Scand (suppl) 145:1-141

Papakostas Y, Stefanis C, Sinouri A, Trikkas G, Papadimitriou G, Pittoulis S (1984): Increases in prolactin levels following bilateral and unilateral ECT. Am J Psychiatry 141:1623-1624

Riddle WJR, Scott AIF, Bennie J, Carroll S, Fink G (1993): current intensity and oxytocin release after electroconvulsive therapy. Biol Psychiatry 33:839-841

Robin A, Binnie CD, Copas JB (1985): Electrophysiological and hormonal responses to three types of electroconvulsive therapy. Br J Psychiatry 147:707-712

Sackeim HA (1994a): Response to the commentaries: Physical properties of the ECT stimulus. Convuls Ther $10(2): 140-152$

Sackeim HA (1994b): Central issues regarding the mechanisms of action of electroconvulsive therapy: Directions for future research. Psychopharmacol Bull 30:281-301

Sackeim HA, Devanand DP (1990): Why we do not know how convulsive therapy works. Comments on "How does convulsive therapy work?" Neuropsychopharmacology 3(2):83-87

Sackeim HA, Prudic I, Devanand DP, Kiersky JE, Fitzsimons L, Moody BJ, McElshiney MC, Coleman EA, Settembrino JM (1993): Effects of stimulus intensity and electrode placement on the efficacy and cognitive effects of electroconvulsive therapy. N Eng J Med 328(12):839-846

Scott AIF, Whalley LJ, Bennie J, Bowler G (1986): Oestrogenstimulated neurophysin and outcome after electroconrulsive therapy. Lancet i:1411-1414 
Sperling MR, Wilson CL (1986): The effect of limbic and extralimbic electrical stimulations upon prolactin secretion in humans. Brain Res 371:293-297

Sperling MR, Pritchard PB III, Engel J, Daniel C, Sagel I (1986): Prolactin in partial epilepsy: An indicator of limbic seizures. Ann Neurol 20(6):716-722

Swartz CM (1993): Beyond seizure duration as a measure of treatment quality. Convuls Ther $9: 1-7$

Swartz CM, Abrams R (1984): Prolactin levels after bilateral and unilateral ECT. Br J Psychiatry 144:643-645
Whalley LJ, Eagles JM, Bowler GMR, Bennie JG, Dick HR, McGuire RJ, Fink G (1987): Selective effects of ECT on hypothalamic-pituitary activity. Psychol Med 17:319-328

Zis AP, Goumeniouk AD, Clark CM, Grant BEK, Remick RA, Lam RW, Garland EJ (1991): ECT-induced prolactin release: Effect of sex, electrode placement and serotonin uptake inhibition. Hum Psychopharmacol 6:155-160

Zis AP, McGarvey KA, Clark CM, Lam RW, Patrick L, Adams SA (1993): Effect of stimulus energy on electroconvulsive therapy-induced prolactin release. Convuls Ther $9(1): 23-27$ 